\title{
Outcome of symptomatic patients undergoing extracardiac Fontan conversion and cryoablation
}

\author{
Samuel Weinstein, $\mathrm{MD}^{\mathrm{a}}$ \\ Cliff Cua, $M D^{b}$ \\ David Chan, MD \\ J. Terrance Davis, MDa
}

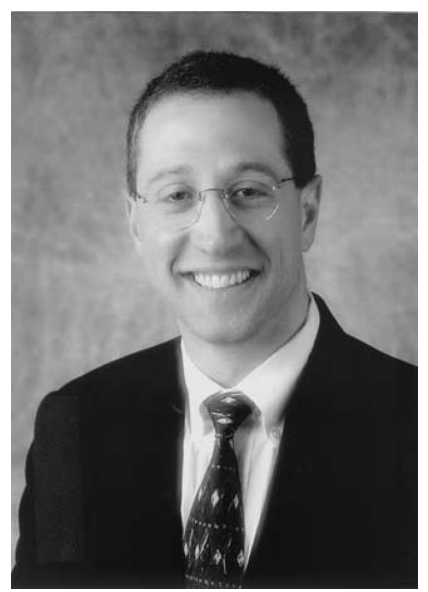

Dr Weinstein
From the Divisions of Pediatric Cardiothoracic Surgery and Cardiology, ${ }^{\mathrm{b}}$ Children's Hospital, Columbus, The Ohio State University Medical Center, Columbus, Ohio.

Received for publication Aug 1, 2002; revisions requested Oct 1, 2002; revisions received Nov 11, 2002; accepted for publication Dec 27, 2002.

Address for reprints: Samuel Weinstein, MD, Department of Thoracic Surgery, Children's Hospital, Columbus, Education Building-Room 642, 700 Children's Drive, Columbus, OH 43205 (E-mail: Weinstes@chi.osu.edu).

J Thorac Cardiovasc Surg 2003;126:529-36

Copyright (C) 2003 by The American Association for Thoracic Surgery

$0022-5223 / 2003 \$ 30.00+0$

doi:10.1016/S0022-5223(03)00212-5
Objective: We review our experience with Fontan conversion and cryoablation in patients with an atriopulmonary Fontan in low cardiac output from arrhythmia or venous obstruction, including 2 patients with protein-losing enteropathy.

Methods: Ten patients (mean age $21.1 \pm 7.0$ years) underwent extracardiac Fontan conversion, cryoablation, and pacemaker placement between November 1999 and April 2002 (13.1 \pm 4.1 years after the original atriopulmonary connection). Eight patients were in New York Heart Association class III and 2 were in New York Heart Association class IV. Nine patients had clinically important intra-atrial reentry tachycardia refractory to medical therapy.

Results: Follow-up was between 3.1 and 32.6 months $(16.8 \pm 9)$. One death occurred at 7 days after surgery due to sepsis and multisystem organ failure. The second death occurred at 48 days from complications of protein-losing enteropathy. The second patient with protein-losing enteropathy had improved New York Heart Association classification, cessation of albumin transfusions, and a normal stool alpha antitrypsin level (down from $4.1 \mathrm{mg} / \mathrm{g}$ preoperatively). Five patients improved to New York Heart Association class I and 3 patients to New York Heart Association class II. Sustained arrhythmias could not be induced in any patient. Seven patients are on no antiarrhythmics. One patient had recurrence of intra-atrial reentrant tachycardia 11 months postoperatively, which required electrical cardioversion; this patient's symptoms are currently well controlled on 1 medication.

Conclusion: Extracardiac Fontan, cryoablation, and pacemaker placement reduced atrial arrhythmias and improved New York Heart Association classification in all surviving patients. In selected patients, this operation offers improvement in clinical outcome and is an alternative to transplantation. Protein-losing enteropathy may not be a contraindication to performing Fontan conversion with cryoablation.

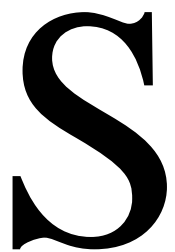

ince the first successful atriopulmonary connection (APC) was reported by Fontan in 1971, the Fontan procedure has been applied to palliate multiple forms of functional single ventricle. ${ }^{1}$ Long-term sequelae of an atriopulmonary Fontan have been well described and include intra-atrial reentrant tachycardia (IART), pulmonary and systemic venous obstruction, thromboembolism, protein-losing enteropathy (PLE), and decreased cardiac output. ${ }^{2-6}$

The increased right atrial flow and suture load that these patients experience from the time of the original Fontan have been felt to be one cause of their atrial arrhythmias. The arrhythmias can further increase right atrial pressure, which leads to a negative cycle that leads to considerable morbidity and mortality. ${ }^{2,3,7}$ Atrial arrhythmias have been reported between $22 \%$ and $50 \%$ of patients with an APC Fontan. ${ }^{2,3,7}$ PLE is seen in between $3.7 \%$ and $10 \%$ of patients but has very high rates of morbidity and mortality. ${ }^{2,5}$ The mortality rate within 5 years of the diagnosis of 
PLE is $40 \% .^{5}$ Although not always clinically apparent, atrial thrombus was reported in $33 \%$ of patients having undergone a variety of different Fontan-type operations. ${ }^{6}$

Total cavopulmonary connection (TCPC) has been one of the modifications to the Fontan operation suggested to improve atrial flow characteristics and hopefully avoid right atrial distention, arrhythmia, and the other long-term sequelae seen with APCs. ${ }^{8,9}$ This adjustment and other modifications, such as fenestration and modified ultrafiltration, have decreased the morbidity and mortality rates from a Fontan operation in the current era, but more time will be needed to evaluate the long-term complications of the TCPC Fontan operation., ${ }^{5,10-13}$

Conversion of an atriopulmonary Fontan to a lateral tunnel or extracardiac Fontan has been attempted to alleviate complications by improving central systemic flow patterns. Many authors hoped that lowering central venous pressure would reduce atrial distention and decrease the presence of atrial arrhythmias. ${ }^{14-16}$ In recent reviews of patients undergoing Fontan revision by conversion to an extracardiac tunnel, half of the patients received no relief from their arrhythmia or had a new arrhythmia develop after the revision surgery. ${ }^{14-16}$ Kreutzer and colleagues, ${ }^{16}$ reviewing the Boston experience, reported on 8 patients undergoing conversion of a modified Fontan to a lateral atrial tunnel Fontan. Two of the 8 patients had PLE, defined in this study as a serum albumin concentration less then $2 \mathrm{~g} / \mathrm{dL}$ with a requirement for albumin replacement at least once every 3 months. Four of 6 patients with an arrhythmia preoperatively still had intra-atrial reentrant tachycardia postoperatively. Additionally, neither of the 2 patients in this study with PLE undergoing Fontan revision had improvement of this condition. ${ }^{16}$

Mavroudis and associates have demonstrated that revision of an APC Fontan, with the addition of cryoablation of the foci of the IART, has markedly improved the outcome for these patients. ${ }^{17-20}$ With a combination of preoperative and intraoperative mapping, Deal and colleagues ${ }^{20}$ have identified the anatomic circuits responsible for the atrial arrhythmias in this cohort of patients. In their most recent report of 40 patients undergoing total cavopulmonary conversion, atrial cryoablation, and permanent pacemaker placement for failed atriopulmonary Fontans, arrhythmia recurrence was only $12.5 \%{ }^{17}$ Right atrial cryoablation was performed in all patients for atrial flutter. Those patients with atrial fibrillation also received left atrial cryoablation, or a Cox maze III procedure. Only $10 \%$ of the patients received long-term antiarrhythmic medications postoperatively, and $85 \%$ of the patients were in New York Heart Association (NYHA) class I or II after the procedure. ${ }^{17}$

Like other institutions, we have struggled with the approach to treating patients with APC Fontans who are symptomatic with IART. We applied Mavroudis' and Deal's approach in our population and we review our ex- perience, which includes 8 patients with intractable IART, 2 with systemic venous obstruction, 2 patients with PLE, and all with poor NYHA classification.

\section{Patients and Materials}

Between November, 1999, and May, 2002, 10 patients (3 men, 7 women) underwent cryoablation and conversion of an APC to an extracardiac Fontan. The age at reoperation was between 12.2 and 32.6 years $(21.1 \pm 7.0$ years $)$ and the interval between original APC to conversion was between 8.7 and 20.9 years $(13.1 \pm 4.1$ years). The initial Fontan was performed between the ages of 1.3 and 20.8 years $(8.3 \pm 6.4$ years $)$. Four patients had a modified Björk procedure, 3 had a bidirectional Glenn shunt with an atriopulmonary anastomosis, 1 had an atriopulmonary anastomosis with a classic Glenn shunt, and 2 had only a right atrial-pulmonary artery conduit (see Table 1). Two patients were formally evaluated for cardiac transplantation but considered poor candidates due to compliance and social issues.

Our current indications for conversion include deteriorating NYHA classification, medically refractory IART, and evidence of systemic venous obstruction. Although we would consider pulmonary venous obstruction an indication, there were no patients with pulmonary venous obstruction presenting in this series. Eight patients were receiving multiple antiarrhythmic agents including various combinations of digoxin, atenolol, sotalol, and amiodarone. Four patients had preoperative electrophysiologic testing and 3 underwent unsuccessful radiofrequency ablation. Six patients required electrical cardioversion up to a maximum of 3 times. Eight patients were in NYHA class III and two were in NYHA class IV. All patients were dyspneic on exertion and had considerable fatigue with minimal exercise.

One patient had a history of thromboembolic events and while awaiting the procedure on the elective schedule was admitted urgently for surgery secondary to a pulmonary embolus. Two patients had a hemodynamically significant systemic venous obstruction, and 1 patient was cyanotic. All patients underwent catheterization before the operation, and their hemodynamic and oxygen saturation data are represented in Table 2 .

Two patients carried a diagnosis of PLE preoperatively. One was a 32-year-old man with tricuspid atresia in whom PLE was diagnosed 1 year after his original Fontan (16 years before his revision surgery.) He received albumin and intravenous gamma globulin therapy every 3 to 4 months and had a stool alpha antitrypsin level of $69.9 \mathrm{mg} / \mathrm{g}$. He was treated chronically with steroids and heparin with limited improvement but was also a noncompliant patient. Frequent infections and cellulitis caused him to be admitted to the hospital several times a year. The second patient with PLE was a 13-year-old girl with pulmonary atresia and intact ventricular septum whose diagnosis was also reached within 1 year of her original Fontan ( 6 years before her revision). After steroid therapy, her admissions to the hospital for intravenous albumin and gamma globulin decreased from 4 times a year to once a year. Her preoperative stool alpha antitrypsin level was $4.1 \mathrm{mg} / \mathrm{g}$.

\section{Operative and Cryoablation Procedure}

The surgical technique applied was similar to that described by Mavroudis and colleagues ${ }^{17-19}$ from Children's Memorial Hospital in Chicago. 
TABLE 1. Patient demographics

\begin{tabular}{|c|c|c|c|c|c|c|}
\hline Patient & Diagnosis & $\begin{array}{c}\text { Age at } \\
\text { Fontan (y) }\end{array}$ & $\begin{array}{l}\text { Interval to } \\
\text { redo }(y)\end{array}$ & $\begin{array}{l}\text { Age at } \\
\text { redo }(y)\end{array}$ & Indication & Outcome \\
\hline 1 & $\begin{array}{l}\text { Tricuspid atresia } \\
\text { VSD }\end{array}$ & 6.8 & 11.3 & 18.1 & NHYA III & NYHA I \\
\hline 2 & Tricuspid atresia & 3.7 & 16.1 & 19.7 & $\begin{array}{l}\text { NYHA III atrial } \\
\text { fib/flutter }\end{array}$ & $\begin{array}{l}\text { NYHA II } \\
\text { nonsustained } \\
\text { IART }\end{array}$ \\
\hline 3 & $\begin{array}{l}\text { Pulmonary atresia } \\
\text { Intact ventricular } \\
\text { septum }\end{array}$ & 4.5 & 9.3 & 13.8 & $\begin{array}{l}\text { NYHA III atrial } \\
\text { flutter }\end{array}$ & $\begin{array}{l}\text { NYHA II } \\
\text { noninducible } \\
\text { IART }\end{array}$ \\
\hline 4 & $\begin{array}{l}\text { Tricuspid atresia } \\
\text { VSD }\end{array}$ & 3.5 & 8.5 & 12.0 & $\begin{array}{l}\text { NYHA IV atrial } \\
\text { flutter PLE }\end{array}$ & $\begin{array}{l}\text { NYHA I } \\
\text { noninducible } \\
\text { IART }\end{array}$ \\
\hline 5 & Tricuspid atresia & 20.9 & 11.4 & 32.3 & $\begin{array}{l}\text { NYHA III SVT } \\
\text { NOS }\end{array}$ & $\begin{array}{l}\text { NYHA II } \\
\text { nonsustained } \\
\text { IART }\end{array}$ \\
\hline 6 & $\begin{array}{l}\text { DILV } \\
\text { Subaortic } \\
\text { chamber } \\
\text { noninducible } \\
\text { IART } \\
\text { Left AV valve } \\
\text { atresia } \\
\text { Malposed great } \\
\text { arteries }\end{array}$ & 16.7 & 11.0 & 27.7 & $\begin{array}{l}\text { NYHA III atrial } \\
\text { flutter }\end{array}$ & NYHA I \\
\hline 7 & Tricuspid atresia & 5.1 & 12.0 & 17.1 & $\begin{array}{l}\text { NYHA III atrial } \\
\text { fib/flutter } \\
\text { PLE }\end{array}$ & Death \\
\hline 8 & $\begin{array}{l}\text { L-TGA } \\
\text { Right AV valve } \\
\text { atresia } \\
\text { VSD } \\
\text { Pulmonary } \\
\text { stenosis }\end{array}$ & 12.8 & 18.0 & 30.8 & $\begin{array}{l}\text { NYHA III atrial } \\
\text { fib/flutter }\end{array}$ & Death \\
\hline 9 & Tricuspid atresia & 1.5 & 19.9 & 21.4 & $\begin{array}{l}\text { NYHA III } \\
\text { systemic } \\
\text { venous } \\
\text { obstruction }\end{array}$ & $\begin{array}{l}\text { NYHA I } \\
\text { noninducible } \\
\text { IART }\end{array}$ \\
\hline 10 & $\begin{array}{l}\text { Tricuspid atresia } \\
\text { VSD }\end{array}$ & 7.9 & 9.8 & 17.7 & $\begin{array}{l}\text { NYHA III atrial } \\
\text { flutter }\end{array}$ & $\begin{array}{l}\text { NYHA I EP testing } \\
\text { pending }\end{array}$ \\
\hline
\end{tabular}

VSD, Ventricular septal defect; DILV, double-inlet left ventricle; L-TGA, levo-transposition of the great arteries; $A V$, atrioventricular; NYHA, New York Heart Association; PLE, protein-losing enteropathy; SVT, supraventricular tachycardia; NOS, nitric oxide synthase; EP, electrophysiologic.

All patients were converted to an extracardiac Fontan (ECF). The conduct for the creation of the TCPC was dictated by the previous atriopulmonary or cavopulmonary connection. Three patients with a bidirectional Glenn shunt had the addition of an extracardiac polytetrafluoroethylene (PTFE) tube graft to the right pulmonary artery, while patients with only an APC underwent both a bidirectional Glenn shunt and an ECF. One patient with a classic Glenn shunt had continuity restored between the right and left pulmonary arteries with homograft tissue before the placement of an extracardiac tube graft from the inferior vena cava (IVC) to the right pulmonary artery. Another patient had both a left and right superior vena cava and both a left and right IVC. This patient underwent bilateral bidirectional Glenn shunts and had an ECF created via a PTFE tube graft to the right pulmonary artery from a constructed confluence of the right and left IVC of autologous atrial tissue.

All ECFs were performed with PTFE grafts of size 20 to 24, and none were fenestrated. Resternotomy with standard technique was performed in all patients. Femoral vessels were dissected electively in 3 patients before resternotomy, and 2 of these patients were placed on groin bypass urgently due to falling saturations and blood pressure during sternal dissection. Once normothermic bypass was instituted the heart was kept beating until all of the relevant vessels for reconstruction were visualized.

Patients underwent transesophageal echocardiography preoperatively, and an intraoperative bubble study was performed to 
TABLE 2. Preoperative catheterization data

\begin{tabular}{|c|c|c|c|c|c|c|c|}
\hline Patient & $\begin{array}{c}\text { RA } \\
(\mathrm{mm} \mathrm{Hg})\end{array}$ & $\begin{array}{c}\text { PA } \\
(\mathrm{mm} \mathrm{Hg})\end{array}$ & $\begin{array}{c}\text { VEDP } \\
(\mathrm{mm} \mathrm{Hg})\end{array}$ & $\begin{array}{c}\text { Rp/Rs } \\
(\mathrm{mm} \mathrm{Hg})\end{array}$ & Os & Op/0s & $\begin{array}{c}\mathrm{O}_{2} \text { sat }(\%) \\
\text { systemic }\end{array}$ \\
\hline 1 & 12 & 12 & 10 & 0.04 & 2.03 & 1.00 & 95 \\
\hline 2 & 12 & 12 & 10 & 0.02 & 1.2 & 1.00 & 92 \\
\hline 3 & 12 & 12 & 13 & 0.07 & 2.4 & 1.00 & 97 \\
\hline 4 & 17 & 14 & 10 & 0.22 & 2.46 & 0.52 & 93 \\
\hline 5 & 23 & 22 & 18 & 0.12 & 2.7 & 1.15 & 90 \\
\hline 6 & 12 & 12 & 5 & 0.04 & 1.64 & 1.13 & 93 \\
\hline 7 & 12 & 12 & 9 & 0.13 & 2.4 & 1.00 & 79 \\
\hline 8 & 22 & 20 & 14 & 0.17 & 2.8 & 1.00 & 90 \\
\hline 9 & 16 & 8 & 11 & 0.08 & 1.47 & 1.32 & 94 \\
\hline 10 & 9 & 9 & 3 & 0.02 & 2.6 & 0.60 & 85 \\
\hline Means $\pm S D$ & $15.3 \pm 4.8$ & $14.5 \pm 4.1$ & $11.1 \pm 3.9$ & $0.10 \pm 0.07$ & $2.17 \pm 0.56$ & $0.98 \pm 0.19$ & $91.1 \pm 5.4$ \\
\hline
\end{tabular}

$R A P$, Right atrial pressure; PAP, pulmonary artery pressure; VEDP, ventricular end-diastolic pressure; $R p / R s$, pulmonary/systemic resistance ratio; $0 s$, systemic blood flow; $Q p / Q$ s, pulmonary/systemic blood flow ratio.

confirm the absence or presence of an atrial septal defect. All patients had right atrial cryoablation performed, although only the 2 patients with atrial fibrillation documented preoperatively received left atrial cryoablation. In an attempt to minimize cardiac ischemic time, patients whose atrial septum was intact underwent cryoablation within the right atrium with the heart beating. After placement of cryoablative lesions, patients were cooled to $28^{\circ} \mathrm{C}$ and the heart was arrested. An atrial septectomy was then performed, and a considerable amount of atrial tissue was excised before atriotomy closure to markedly reduce atrial cavity size. Previous right atrial suture lines, as in a Björk modification, were excised when not included within the cryoablation lines. After atrial closure, all hearts were reperfused and the specific type of Fontan revision for that patient was carried out with the heart beating and patient rewarming.

The right atrial cryoablation lesions were placed in 4 distinct locations as described by Mavroudis and colleagues ${ }^{19}$ : (1) between the posterior rim of the atrial septal defect to the posterior edge or resected atrial wall; (2) between the superior aspect of the ASD and the area of resected right atrial appendage; (3) from the IVC to the rim of the coronary sinus os; and (4) from the IVC to the annulus of the right-sided atrioventricular valve (Figure 1).

Two patients with atrial fibrillation underwent cryoablation in the left atrium. Left atrial cryoablation was performed in the arrested heart before atrial closure. These lesions were placed as follows: (1) encircling the pulmonary veins, (2) from the pulmonary veins toward the mitral valve annulus, and (3) at the orifice of the left atrial appendage (Figure 2).

Lesions were laid down for 90 seconds at $-60^{\circ} \mathrm{C}$. A $15-\mathrm{mm}$ flat-faced Cooper surgical probe was used for the initial patients in our series, but subsequently our approach changed to the use of 2 linear probes for greater efficiency (Figure 3). Intraoperative mapping was not performed.

Permanent DDD pacemakers were placed in all but 1 patient. When possible, steroid-eluting epicardial leads were used; however, 1 patient received an active fixed helical lead due to poor initial pacing thresholds on the ventricle. Two patients had their atrial lead placed within the left atrium at the time of atrial septectomy because of concern of the lack of availability of surface atrial tissue. Programming of the pacemaker was individ- ualized to the age of the patient. In all patients the lower rate was set at 70 beats/min or higher to optimize cardiac output and atrioventricular synchrony. The patient who did not receive a permanent pacemaker had limited atrial tissue, poor initial sensitivity and threshold values, and preserved sinus node function after surgery. She has remained in sinus rhythm over 1 year after surgery, and we have elected not to reoperate for a pacemaker.

\section{Results}

Data were obtained from patient charts and patient and family member reports. All patients with a permanent pacemaker underwent electrophysiologic study to assess inducibility of postoperative intra-atrial reentrant tachycardia.

Mean follow-up was between 3.1 and 32.6 months (16.8 \pm 9.5 months). There were 8 survivors and 2 deaths. All survivors had improved NYHA classification. Of the 8 survivors, 5 patients are currently classified NYHA class I and 3 are NYHA class II (Figure 4).

Mean cardiopulmonary bypass time in our cohort was $232 \pm 72$ minutes and mean crossclamp time was $51 \pm 23$ minutes. One patient underwent a brief period of circulatory arrest of 14 minutes to improve visualization of the right pulmonary artery due to a large amount of collateral flow. Another patient required additional surgery to drain a seroma in a groin dissection site. One patient required revision of a pacemaker generator site due to pectoralis muscle stimulation. A second patient required reexploration for postoperative bleeding from a pulmonary adhesion and was extubated for 4 hours after surgery.

One patient died 7 days postoperatively of sepsis and multisystem organ failure. This patient had a history of mediastinitis with secondary healing of her sternum from her original APC. Her conversion surgery was notable for a lengthy dissection of her mediastinal adhesions, reconstruction of bilateral superior vena cava, bilateral IVC, and she required reexploration for postoperative hemorrhage. On postoperative day 4 she cultured positive for Staphylococ- 


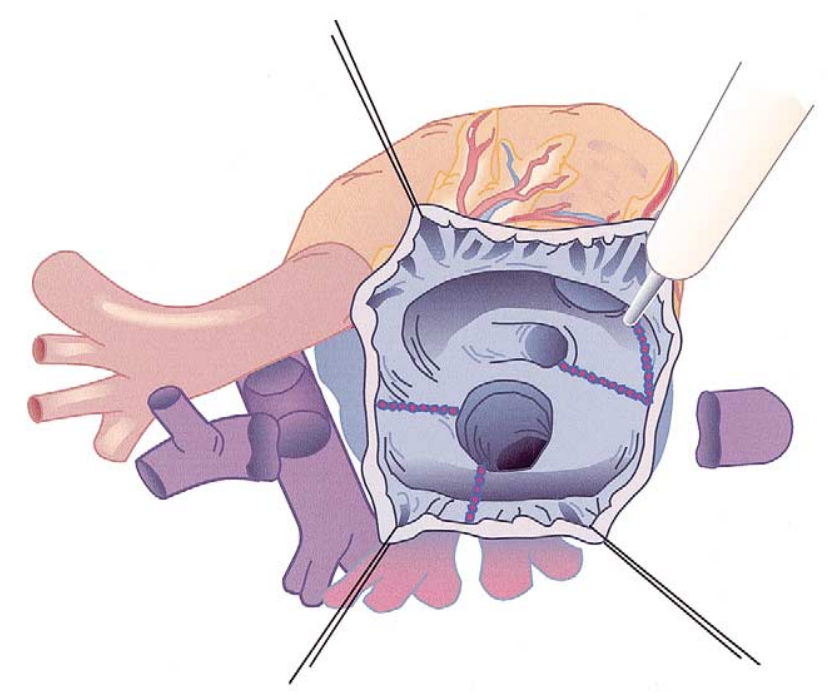

Figure 1. Lesions are placed in 4 locations at $-60^{\circ} \mathrm{C}$ for 90 seconds each. In this patient with severe tricuspid stenosis a linear cryoprobe is used to ablate tissue between the ASD and the superior vena cava, the ASD and the lateral edge of the atriotomy, the coronary sinus os and the cut edge of the IVC, and the area of the tricuspid valve annulus and IVC.

cus aureus, as she did after her initial APC. The other patient who died was 1 of the 2 patients in this series with PLE. This patient showed significant improvement in his cardiac output and IART control but continued to have drainage of serous fluid from his mediastinal wound and femoral vessel dissection site. He received multiple transfusions of albumin and gamma globulin without clinical improvement. Despite severe malnutrition he refused enteral or parenteral nutrition. At postoperative day 42 he was readmitted to the hospital with malnutrition and sepsis. On day 48 after surgery, he died of sepsis and multisystem organ failure.

The other patient in our series with PLE has shown remarkable improvement. Now 14 years old, she no longer requires albumin transfusion therapy. Her last stool alpha antitrypsin level was $2.6 \mathrm{mg} / \mathrm{g}$, down from $4.1 \mathrm{mg} / \mathrm{g}$ preoperatively (normal $\leq 2.6 \mathrm{mg} / \mathrm{g}$ ). Her exercise tolerance has improved substantially. Wheelchair-bound preoperatively, she now participates in school gym class. She is currently undergoing a slow taper of steroids, which she continues to use for arthritic symptoms.

IART was not present in any patient at the time of discharge. Patients with permanent pacemakers underwent electrophysiologic testing via their pacing system within 2 months of surgery to determine the inducibility of IART. Standard pacing protocols using extrastimuli of singles, doubles, and triples were applied. Four patients were not inducible. Two patients had nonsustained atrial tachycardia

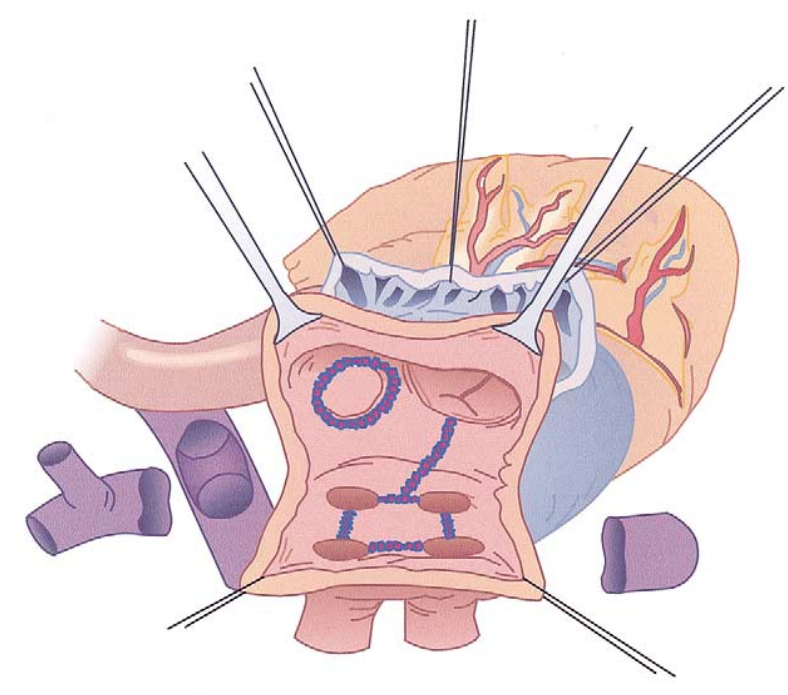

Figure 2. Left-sided cryoablations are placed for patients with preoperative atrial fibrillation around the pulmonary veins, at the orifice of the left atrial appendage, and between the inferior pulmonary veins and the mitral valve annulus.

induced, defined as less than 1 minute. No patient has had a significant atrial arrhythmia by clinical history.

One patient with giant atria, pulmonary embolism, and atrial fibrillation/flutter has had no episodes of tachyarrhythmia postoperatively for 1 year but recently had antiarrhythmic therapy restarted with sotalol for paroxysmal episodes of IART. This patient has had no further thromboembolic events since surgery ( $>24$ months). His chest $\mathrm{x}$-ray films preoperatively and postoperatively represent the potential nidus for thrombus formation and the substantial change seen in atrial cavity size after atriectomy (Figure 5).

\section{Discussion}

For patients with deteriorating function after an APC Fontan, the options include medical treatment, surgical revision, or cardiac transplantation. Medical therapy for IART has a high failure rate ${ }^{21}$ and catheter-based radiofrequency ablation often requires repeat interventions. ${ }^{22,23}$ Additionally, these therapies do not address other potential sources of decreased cardiac output such as giant right atrium and systemic or pulmonary venous obstruction. Surgical revision of a Fontan alone, without cryoablation, addresses only the anatomic pathology resulting in poor hemodynamics and does not ablate the substrate for the reentrant arrhythmias. Intra-atrial reentrant tachycardia is seen after surgical revision of a Fontan without cryoablation, with its attendant morbidity. ${ }^{4,14-16,24}$

There is considerable data suggesting that interruption of IART with cryoablation in a failed Fontan, in addition to right atrial reduction and conversion to an extracardiac 


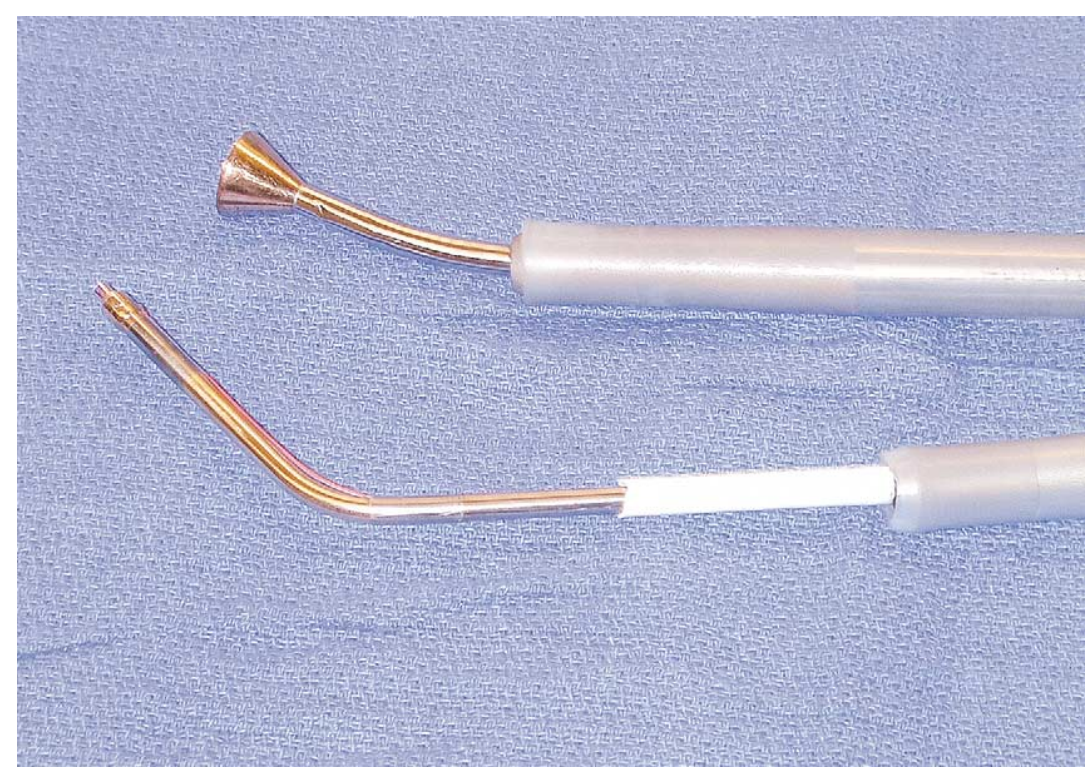

Figure 3. A linear and 15-mm round head cryoprobe.

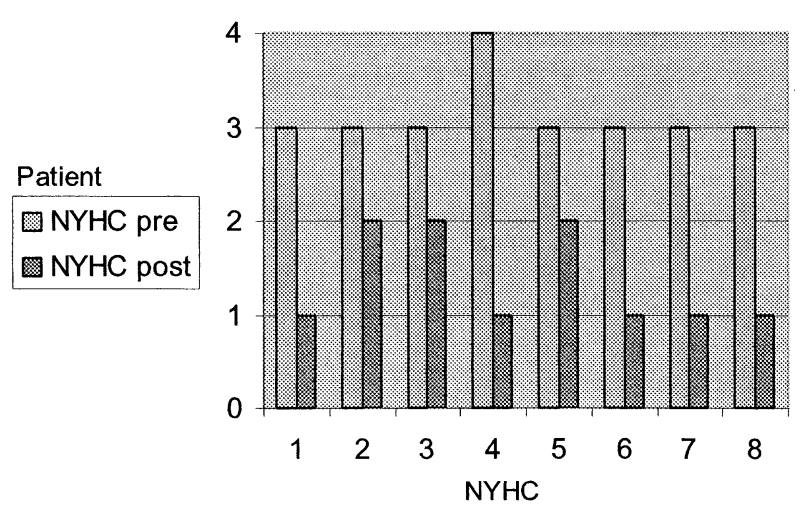

Figure 4. New York Heart Association classification preoperatively and postoperatively.

connection, will result in superior hemodynamics and an improvement in IART management. ${ }^{14-20,25,26}$

In comparison, conversion of an atriopulmonary Fontan to a total cavopulmonary Fontan without arrhythmia circuit cryoablation has been shown to result in a very high level of recurrence. ${ }^{14-18}$ Deal and colleagues, ${ }^{20}$ in 1998, reported a comparison of patients from the same center undergoing Fontan revision with and without concomitant cryoablation. All patients who underwent revision alone experienced recurrent symptomatic atrial tachycardia, while the group having cryoablation had only a $10 \%$ recurrence rate. ${ }^{20} \mathrm{Ma}-$ vroudis' group ${ }^{19}$ and Deal's group ${ }^{20}$ have impressively mapped the areas where there is substrate for the production of reentrant circuits in the right atrium. Their work has followed the extensive work by Gandhi and colleagues, ${ }^{25,26}$ who in a canine model showed that surgical incisions from the Fontan are the nidus for the arrhythmia and that interruption of these areas are necessary to effectively treat the IART.

We believe that our experience compares favorably with previous reports of Fontan conversion and cryoablation. In our series, surviving patients clearly have improved hemodynamics, and all but 1 patient has been relieved of the burden of antiarrhythmic medication. This patient is well controlled on 1 medication. We have had 2 mortalities in this group of 10 patients. The Chicago group has seen 1 death and 3 patients go on to transplantation, suggesting a treatment failure of $10 \%$ in their last reported series of 40 patients. ${ }^{17}$ Our higher failure rate may be due to the older age of our patients at presentation for surgery, the small number of patients in our series, or the inclusion of patients with PLE.

We believe that this is the first report of Fontan conversion and cryoablation being performed in patients with PLE. One of our 2 patients with PLE did show a complete resolution of her dependency on chronic infusion therapy. She was in NYHA class IV before operation and improved to NYHA class I after the procedure. Her heparin, albumin, and intravenous immunoglobulin transfusions have been discontinued and her last stool alpha antitrypsin level was normal.

Although we cannot recommend Fontan conversion with cryoablation as specific therapy for PLE, we do not feel that the presence of PLE is a contraindication to the procedure if arrhythmia or hemodynamic data suggest that the surgery is indicated. Both patients with PLE had gradients from right atrium to pulmonary artery of 2 and $3 \mathrm{~mm} \mathrm{Hg}$, which were relieved with an extracardiac tube. The surviving patient 

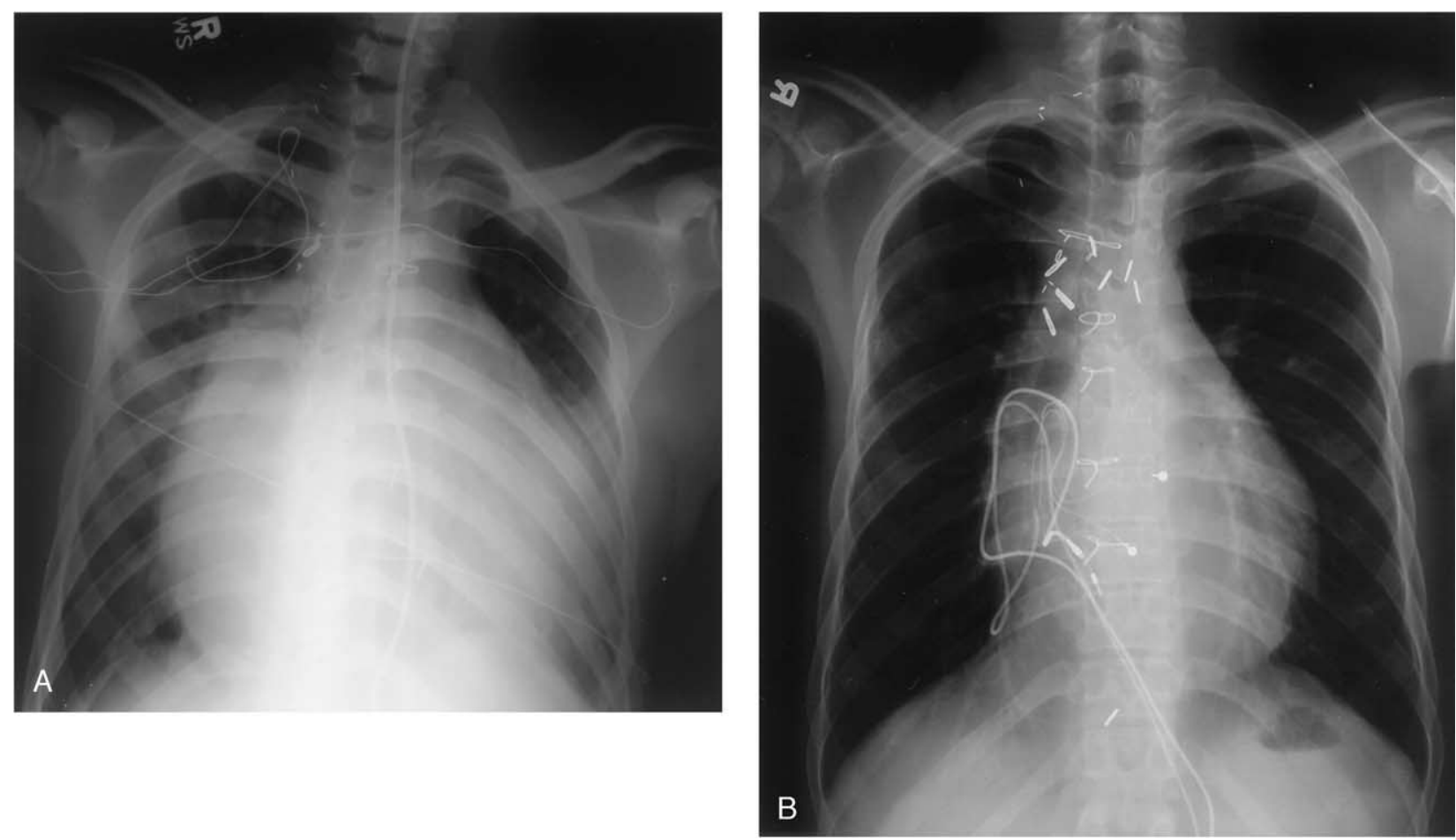

Figure 5. These preoperative and postoperative chest radiographs represent the substantial decrease in size of the right atrium in a 20 -year-old man undergoing Fontan revision, right and left cryoablation, and right atriectomy. The patient's original Fontan was a common atrial-right pulmonary artery connection with a Björk modification. This patient had recurrent pulmonary emboli from stagnant flow in his right atria. The decrease in size of theidus for clot formation and improved hemodynamics are well demonstrated by the change in cardiac silhouette.

had more severe atrial arrhythmias, but both patients' IART was well controlled after cryoablation. The surviving patient was younger, with reasonable medical control of her PLE, and the patient who succumbed was over 30 years old, with severe ascites and poor compliance with medical therapy for over a decade. These factors may present a variable that relates to why 1 patient's PLE resolved while the other patient died of complications from the same disease.

The patient with a history of cerebral vascular accidents and recurrent pulmonary emboli has seen significant relief from both his recurrent pulmonary emboli and intra-atrial reentrant tachycardia. He has not had a thromboembolic event more than 2 years since surgery and his atrial fibrillation and flutter are well controlled.

We elected to perform right atrial cryoablation on every patient, including 2 patients who did not have IART preoperatively. Our group feels this is the proper approach based on Deal and colleagues' work ${ }^{20}$ in identifying the anatomic circuits responsible for IART in patients with APC Fontans. Previous right atrial suture lines are resected during the procedure and it adds little technically to perform cryoablation within the right atrium. Currently, we choose not to add left atrial cryoablation in the absence of atrial fibrilla- tion. This requires opening the left atrium and increasing cardiac ischemic time.

None of the patients in this series received a fenestrated Fontan. As well, patients in whom the pulmonary artery was still connected to the heart resulting in some percentage of pulsatile flow did not receive a pulmonary artery disconnection. We believe that adult patients with a preexisting Fontan represent a different cohort physiologically than the typical 2- or 3-year-old child coming for a Fontan operation today. These adult patients have already made their transition to passive pulmonary blood flow and have proven that Fontan physiology will be tolerated. We have not seen these adolescent and adult patients experience pulmonary vascular reactivity affecting their cardiac output. In addition, we have found that fenestrations in extracardiac Fontans do not stay open as long or as reliably as in a lateral tunnel Fontan.

DDD pacemakers were placed in 9 patients. Although the Chicago group places atrial antitachycardia pacemakers only, we were worried in our early experience that our patients might experience atrioventricular node dysfunction. Transvenous access for a ventricular lead after this surgery would be difficult, and placement would require a thoracotomy. Currently, 2 patients are in sinus rhythm, 2 are ven- 
tricular sensing and atrial pacing, and 4 patients are pacing both atria and ventricles.

We believe that this procedure is effective in improving a patient's symptoms of heart failure and in reducing the recurrence of IART. Based on the improvement in NYHA failure classification for all surviving patients, we believe there is clinical evidence that cardiac output is improved.

Transplantation can offer a viable option in this patient population. However, the success of pediatric cardiac transplantation is equivalent to the reported results of Fontan revision and cryoablation, ${ }^{17,27,28}$ as well as our center. In addition, the morbidity rates of transplantation in Fontan patients have been noted to be higher than for other subgroups undergoing cardiac replacement therapy. ${ }^{27}$ The morbidity and mortality rates associated with immunosuppression, in addition to the limited availability of organs for transplantation, would suggest that surgical conversion with cryoablation is preferable in this subset of patients. This approach results in clinically important palliation of patient symptoms and does not preclude cardiac transplantation as a future option. We currently offer Fontan conversion with cryoablation for this cohort of patients before considering transplantation.

\section{Conclusion}

We agree with previous reports that Fontan revision with cryoablation improves the clinical outcome for patients with IART and low cardiac output. This procedure may be an alternative to cardiac transplantation or may act as a bridge to transplantation. We suggest that in a patient who otherwise meets criteria for Fontan conversion and cryoablation, PLE may not be a contraindication to performing surgery. Fontan conversion with cryoablation can result in improvement in symptoms of PLE.

\section{References}

1. Fontan F, Mounicot FB, Baudet E, et al. "Correction" de L'Atresia Tricuspidienne: rapport de deux cas "corriqes" par 1'utilisation d'une technique chirurqicale nouvelle. Ann Chir Thorac Cardiovasc. 1971; 10:39-47.

2. Driscoll DJ, Offord KP, Feldt RH, et al. Five- to fifteen-year follow up after Fontan operation. Circulation. 1992;85:469-96.

3. Cromme-Dijkhuis AH, Hess J, Hahlen K, et al. Specific sequelae after Fontan operation at mid- and long term follow-up. J Thorac Cardiovasc Surg. 1993;106:1126-32.

4. Coon PD, Rychik JR, Novelo RT, et al. Thrombus formation after the Fontan operation. Ann Thorac Surg. 2001;71:1990-4.

5. Mertens L, Hagler DJ, Sauer U, et al. Protein losing enteropathy after the Fontan operation: an international multicenter study. J Cardiovasc Surg. 1998;115:1063-73.

6. Balling G, Vogt M, Kaemmerer H, et al. Intracardiac thrombus formation after the Fontan operation. J Thorac Cardiovasc Surg. 2000; 119:745-52.
7. Treidman JK, Saul JP, Weindling SN, Walsh EP. Radiofrequency ablation of intra-atrial reentrant tachycardia after surgical palliation of congenital heart disease. Circulation. 1995;91:707-14.

8. de Leval MR, Kilner P, Gewillig M, et al. Total cavopulmonary connection: a logical alternative to atriopulmonary connection for complex Fontan operations. J Thorac Cardiovasc Surg. 1988;96:68295.

9. Balaji S, Gewillig M, Bull C, et al. Arrhythmias after the Fontan operation. Circulation. 1991;84(Suppl III):III162-7.

10. Gentles TL, Mayer JE, Gauvreau K, et al. Fontan operation in five hundred consecutive patients: factors influencing early and late outcome. J Thorac Cardiovasc Surg. 1997;114:376-91.

11. Mosca RS, Kulik TJ, Goldberg CS, et al. Early results of the Fontan procedure in one hundred consecutive patients with hypoplastic left heart syndrome. J Thorac Cardiovasc Surg. 2000;119:1110-8.

12. Van Arsdell GS, McCrindle BW, Einarson KD, et al. Interventions associated with minimal Fontan mortality. Ann Thorac Surg. 2000;70: 568-74.

13. Stamm C, Friehs I, Mayer JE, et al. Long-term results of the lateral tunnel Fontan operation. J Thorac Cardiovasc Surg. 2001;121:28-41.

14. McElhinney D, Reddy VM, Moore P, et al., Revision of previous Fontan connections to extracardiac or intraatrial conduit cavopulmonary anastomosis. Ann Thorac Surg. 1996;62:1276-1283.

15. Vitullo DA, DeLeon SY, Berry TE, et al. Clinical improvement after revision in Fontan patients. Ann Thorac Surg. 1996;61:1797-804.

16. Kreutzer J, Keane JF, Lock JE, et al. Conversion of modified Fontan to lateral atrial tunnel cavopulmonary anastomosis. $J$ Thorac Cardiovasc Surg. 1996;111:1169-76.

17. Mavroudis C, Backer CL, Deal BJ, et al. Total cavopulmonary conversion and maze procedure for patients with failure of the Fontan operation. J Thorac Cardiovasc Surg. 2001;122:863-71.

18. Mavroudis C, Backer CL, Deal BJ, et al. Fontan conversion to cavopulmonary connection and arrhythmia circuit cryoablation. $J$ Thorac Cardiovasc Surg. 1998;115:547-56.

19. Mavroudis C, Deal BJ, Backer CL, Johnsrude CL. The favorable impact of arrhythmia surgery on total cavopulmonary artery Fontan conversion. Semin Thorac Cardiovasc Surg Pediatr Card Surg Annu. 1999;2:143-56.

20. Deal BJ, Mavroudis C, Backer CL, et al. Impact of arrhythmia circuit cryoablation during Fontan conversion for refractory atrial tachycardia. Am J Cardiol. 1999;83:563-68.

21. Balaji S, Johnson TB, Sade RM, et al. Management of atrial flutter after the Fontan procedure. J Am Coll Cardiol. 1994;23:1209-15.

22. Kalman JM, VanHare GF, Olgin JE, et al. Ablation of incisional reentrant atrial tachycardia complicating surgery for congenital heart disease. Circulation. 1996;93:502-12.

23. Lesh MD, Van Hare GF, Epstein LM, et al. Radiofrequency catheter ablation of atrial arrhythmias-results and mechanisms. Circulation. 1994;89:1074-89.

24. Kao JM, Alejos JC, Grant PW, et al. Conversion of atriopulmonary to cavopulmonary anastomosis in management of late arrhythmias and atrial thrombosis. Ann Thorac Surg. 1994;58:1510-4.

25. Gandhi SK, Bromberg BI, Rodefeld MD, et al. Lateral tunnel suture line variation reduces atrial flutter after the modified Fontan operation. Ann Thorac Surg. 1996;61:1299-309.

26. Gandhi SK, Bromberg BI, Schuessler RB, et al. Characterization and surgical ablation of atrial flutter after the classic Fontan repair. Ann Thorac Surg. 1996;61:1666-979.

27. Lamour JM, Addonizio LJ, Galantowicz ME, et al. Outcome after orthotopic cardiac transplantation in adults with congenital heart disease. Circulation. 1999;100(19 Suppl):II200-5.

28. Menkis AH, McKenzie FN, Novick RJ, et al. Expanding applicability of transplantation after multiple prior palliative procedures. Ann Thorac Surg. 1991;52:722-6. 